\title{
Bartra, Eli y Huacuz Elías, María Guadalupe (Coords.) (2015): Mujeres, feminismo y arte popular. Ciudad de México: Obra Abierta Ediciones. 191 pp. ISBN: 9786079209292.
}

'Mujeres, feminismo y arte popular' es una obra coordinada por Eli Bartra y María Guadalupe Huacuz Elías. Pero no es una mera compilación de textos, sino que es un muy necesario recorrido por la travesía de las realidades de las mujeres que dedican su cuerpo y su ser a crear, en la sombra y en la discriminación, lo que se viene denominando como arte popular.

Esta compilación de textos nos evoca la necesaria transversalidad del género en todas las realidades sociales, sobre todo en aquellos contextos donde el feminismo no es un espacio de pensamiento sólo de salón -academista-, sino una forma de acción, reivindicación, vida y cotidianeidad donde caben todas las mujeres, caso como es el de las mujeres que invisibles y de manera anónima trabajan en los talleres creando arte.

El epígrafe de la introducción del libro no te deja impasible. Marca de manera directa la necesaria inclusión del feminismo en el arte popular. Lo ineludible que es incluir la perspectiva de género en el análisis de los procesos y espacios sociales de creación, distribución y consumo del arte popular en América, sobre todo haciendo especial énfasis en México.

En el Arte popular el género está completamente presente, en todas sus fases. En este sentido esta obra toma una mayor importancia social y antropológica, en el caso de lo social por tratarse de un colectivo, el de las mujeres artistas, que en la mayor parte de las ocasiones - por no decir su totalidad- son mujeres en situaciones económicas precarias. En lo que refiere a lo antropológico la riqueza del arte se deja entrever en cómo sus vidas, sus culturas, sus raíces y su trabajo está íntimamente ligado con su origen, su lugar y como no el sentir de sí mismas como artistas.

La obra se compone de cuatro partes, las cuales a su vez integran una serie de capítulos, perfectamente hilados con el objetivo de esta obra: hacer ver lo necesario que es incluir la perspectiva de género y el feminismo en los espacios del arte popular.

La primera parte, titulada pretextos y textos, incluye cinco artículos. El primero de ellos Apuntes sobre feminismo y arte popular cuya autora es Eli Bartra demuestra esa necesaria inclusión del feminismo y del género en lo que denominamos arte popular. La autora hace un alarde de su gran experiencia como teórica no sólo del género sino del arte y la antropología, mostrando una vez más no sólo la invisibilidad del género en la sociedad en general, y en particular en el mundo del arte sino, mostrando la invisibilidad del arte popular en el mundo del arte. Mujer y arte popular parecen ser que son dos cuestiones complicadas de ser nombradas, haciéndose invisibles a ojos de la sociedad -añado patriarcal- dos cuestiones íntimamente unidas, tal y como veremos en el resto de capítulos. Este texto hace énfasis en la inexistencia de un locus teórico estructurado sobre el arte popular en sí mismo y su relación con el género, haciendo un llamamiento a la necesidad de estudiar cada uno de los procesos que rodean al arte popular en su contexto social determinado, no de forma a histórica, a modo de objeto sin un sujeto que lo crea. El capítulo I es la perfecta "Opertura" de esta obra.

El capítulo II Arte popular y género, cuyas autoras son Anabella Barragán Solís y María Guadalupe Huacuz Elías analizan desde la perspectiva de género tres aspectos propios del arte popular Otomí -Municipio de Amealco, Querétaro- para lo cual retoman una serie de cuestiones que planteó Eli Bartra en su obra Mosaico de creatividades. Experiencias de arte popular (2013). Cuestiones a considerar: quienes son las personas que crean el arte; cuáles son los procesos de creación, distribución y consumo del arte; cuál es la participación de las mujeres en el proceso creador y por último Cuáles son las diferencias y similitudes entre hombres y mujeres en las formas de creación de sus obras. A estas cuestiones ellas van dando respuesta realizando un detallado análisis etnográfico sobre la creación de las muñecas de Santiago Mexquititlán, los bordados, telas -fabricación textil- y ornamentos producidos con fibra de nopal propios de la Región anteriormente mencionada. Ellas definen a esos objetos de arte popular como elementos de identidad, pero que viene a ser oportunidades de empleabilidad y tecnificación o modernización de algunos trabajos, en producciones donde la comunidad familiar, en su completitud, colaboran y trabajan.

En el capítulo III Formas, tendencias y valores del patchwork afroamericano de los Estados Unidos de Norteamérica (Siglos XVIII-XXI) escrito por Geraldine Chouard quien analiza una forma de arte popular ya clásico en Norteamérica elaborado por mujeres afroamericanas consistente en ir cosiendo trozos de tela de diferentes colores y formas con el fin de crear objetos únicos. Arte popular que muestran cómo la identidad de la mujer afrodescendiente, otrora esclavas, está impregnada en los quilt que cosían y cosen, piezas que no tienen patrón, que cuentan historias como era el caso de los Bible quilts y los Protest quilts. Retazos de tela que dicen mucho más que una tela cosida pues forman parte de la historia, de la cultura y la contra cultura de un país.

El capítulo IV titulado Mujer, arte popular y cosmología" firmado por Patricia Moctezuma Yano, es un análisis de un conjunto escultórico que es conocido como "Juego de aire", estas esculturas propias del 
barrio de Santa Ana de la comunidad de Tlayacapan Morelos-, creadas de barro y de formas muy delicadas, por lo que son difíciles de encontrar y fabricar, además de contar con pocas alfareras que se dediquen a ello, tienen una doble función en el arte popular. Por un lado son creaciones artísticas y por otro lado son curativas. Patricia Moctezuma Yano mostrará en este trabajo los atributos que les son inferidos a estas piezas, no sólo los estéticos sino los terapéuticos, orientados a la sanación de las dolencias espirituales. En todo ello resalta el papel de las mujeres mayores, las cuales son las que elaboran las piezas de barro y el desarraigo, alteración y pérdida de tradiciones milenarias que están unidas a estos procesos de creación y sanación derivado del advenimiento del turismo a la región, lo cual hace que los "juegos de aire" corran el riesgo de convertirse en mercancías o souvenirs, perdiendo la identidad de quien los crea, para qué los crea y cómo los crea.

Esta primera parte es cerrada por el capítulo V. Lacas. Pázcuarco, Michoacán. Cuya autora Beatriz Ortega artista creadora desde hace tiempo de Lacas nos demuestra con su testimonio la discriminación que, por el mero hecho de ser artesana mujer ha sufrido. Un testimonio que no te deja impasible pues, el periplo por el cual pasa a lo largo de toda su carrera como artista demuestra y muestra la necesaria lucha por el lugar que la mujer ha de ocupar en los espacios de creación. Haciendo un llamamiento a todas las demás artistas a reivindicar sus derechos como tales y a alzar sus voces contra la discriminación y el anonimato e invisibilidad en las que se hayan sumidas.

La segunda parte del libro, Tejidos, puntadas hechura y circulación, comienza con el capítulo VI Artesanías en México, producciones, consumos y mercados, su autora Victoria Novelo platea una pregunta que hará de hilo conductor durante todo el capítulo a considerar: ¿Cómo les va a decenas de miles de personas, tanto hombres como mujeres, que producen de manera artesanal o lo que es lo mismo de forma manual, en México? Con esta pregunta demuestra que en México las artesanías son producidas en su mayoría por comunidades indígenas y campesinas de los estados más deprimidos económicamente hablando. La pobreza y el arte popular parece que están unidos y son las maneras domésticas de supervivencia de multitud de personas, las cuales producen las obras de arte popular a modo de actos de su vida cotidiana, de sus rituales ceremoniales. Comunidades que le permiten a la autora de este texto analizar las tipologías de trabajo artesanal, las consecuencias y características, pues en dicho análisis puede ver cómo se implican los miembros de la comunidad en la distribución y en el consumo.

El capítulo VII Uma ofrenda: bordados brasileiros para Frida Kahlo cuya autora es Elda Eggert presenta una reflexión basada en los bordados que la creadora Ivone Junqueira, inspirándose en tres de las obras de Frida Kahlo "Unos cuantos piquetitos", "Columna rota" y "Las dos Fridas". Ivone Junqueira realizó una serie de representaciones de esos cuadros en telas bordadas por ella, entremezclando sus propias experiencias con las narradas por Frida Kahlo en dichas obras. Un texto que no sólo une culturas -como es la Brasileira y la Mexicana- sino que une biografías, identidades y creatividad de dos artistas.

Bordados por la Paz Guadalajara: tejiendo narraciones estético políticas contra la violencia de México, capítulo VIII de esta obra y firmado por Cristina Reyes Iborra nos describe el análisis que se han realizado de las representaciones en algunos pañuelos de tela, los cuales en la mayoría de las veces han sido elaborados por el grupo reivindicativo y social "Bordados por la Paz. Guadalajara". Mediante estas creaciones -pañuelos pintados- se denuncian las situaciones de violencia que se viven en la ciudad de Guadalajara, así como en otras partes de México. Estos pañuelos son expuestos en multitud de espacios públicos -plazas, jardines públicos, etc., con el fin de concienciar y visibilizar las historias y el día a día de las víctimas de violencia. Cristina Reyes considera que algunos de esos pañuelos transcienden el hecho de ser objetos artísticos para convertirse en herramientas de protesta y reivindicación. Los considera arte grupal capaz de reconstruir las relaciones sociales que han sido descompuestas o destruidas por la violencia.

El testimonio de la artesana Josefina Jiménez, autora del capítulo IX, Cooperativa de mujeres de Teotitlán del Valle, Oaxaca. Nos muestra como es la experiencia de ella como artesana de una cooperativa de tejedoras de sarapes de la localidad de Teotitlán del Valle. Una experiencia muy valiosa sobre todo a la hora de comprender las formas en las que se organizan, las complicaciones que han tenido como mujeres zapotecas -es aquí donde el género se entrecruza con la etnia y el indigenismo- a la hora de organizarse en cooperativas, pues el hecho de ser mujeres e indígenas suponía que hacer una cooperativa derivaba en la descalificación y rechazo comunitario, familiar y de las autoridades de la Comunidad. Este relato es reflejado en las palabras de la autora "comenzamos a caminar solas". Un texto que muestra una vez más la lucha de las mujeres por conseguir el reconocimiento de sus comunidades como creadoras, teniendo que enfrentarse a las problemáticas que por ser mujeres e indígenas se han encontrado en el mercado contemporáneo, el cual lo único que trata es de disolver las manifestaciones del arte popular.

La tercera parte del libro sobre factos y arte-factos, se divide en cinco capítulos. El capítulo $X$ Josefina Aguilar. Autorretrato, cuya autora es Liliana Elvira Moctezuma hace un repaso biográfico y artístico de Josefina Aguilar Alcántara, creadora nacida en 1945, quien con sus manos y una espina de marguey crea obras de arte popular. Liliana centra su análisis de la artista en su obra Autorretrato, donde la creadora se reconoce y expresa como artista. Este autorretrato le permite a la artista reflejarse como mujer y poder darle significado a las cosas de su vida cotidiana, aquellas que la rodean y que le infieren una identidad. Cosas como son su familia, su trabajo y su propia comunidad. 
En este trabajo y en el trabajo de la creadora se destaca la semejanza que existe entre Josefina y Frida Kahlo, pues ambas se acercaron en sus obras a una expresión autobiográfica, narrando su vida como mujer.

Las mujeres y la violencia de los exvotos pintados: una perspectiva de género es el capítulo XI firmado por María J. Rodríguez-Shadow y Liliana Campos Rodríguez. En este capítulo se parte del análisis de las imágenes votivas 0 exvotos procedentes de colecciones privadas y algunos de los que están expuestos en santuarios mexicanos y el grado de violencia machista que quedan representados en dichas pinturas - puesto que lo que analizan son los exvotos pictóricos-. Ambas autoras concluyen en que en esas pequeñas obras, desdeñadas por el espacio del arte formal y academista, pues muchas carecen de una estética y técnica pictórica profesional, y que son ofrendadas por mujeres a una imagen divina -sea un santo, virgen o cristo- dejan ver un universo simbólico de preocupaciones cotidianas, domésticas y del día a día tales como son la violencia conyugal. Estos pequeños cuadros votivos muestran a través de la expresión artística un mundo íntimo y personal de la sociedad y sobre todo un problema muy generalizado: la violencia machista.

El capítulo XII Os repassos nos teares manuais: a inventabilidade das tecedoras de Minas Gerais. Firmado por Amanda Motta Castro, se centra en mostrar cómo ocurre el proceso educativo de las mujeres que enseñan y aprender a tejer manualmente en el municipio de Resende Costa -Estado de Minas Gerais, Brasil- Este trabajo se centra principalmente en los estudios feministas que parten del concepto de educación popular. En el caso que es estudiado se ve claramente cómo la comunidad femenina establece redes de aprendizaje y cooperación donde la pedagogía o el aprendizaje de una labor tradicional es el eje de la comunidad femenina.

De la alfarería de uso doméstico al arte popular: las artesanas de Santa María Atzompa, innovando. Cuya autoría recae en María Elena Lopes Pacheco y que corresponde al capítulo XIII, hace mención a la actividad transformadora de las artesanas de dicha comunidad de Oaxaca, quienes con barro y otras herramientas crean esculturas decoradas y demás objetos de uso cotidiano y doméstico pero con el fin de transformarlos en objetos artísticos ornamentales. Esta es una actividad artesanal que ha enriquecido a las mujeres y las ha empoderado en la producción alfarera de su comunidad a fuerza de luchar dentro de su propio grupo por desarrollar esta actividad creativa, modificando las esculturas domésticas y los objetos que producen. Entre las innovaciones que María Elena menciona están la incorporación de mitos y leyendas populares dentro de la comunidad, la transformación de los objetos de uso cotidiano y doméstico en arte popular mediante el uso de nuevas técnicas de elaboración. Además entre las innovaciones debemos mentar cómo las creadoras incluyen en sus obras parte de su propia identidad y vivencias pues, muchas artistas expresan en sus trabajos la visión que ellas tienen del mundo, sus sueños y vivencias, lo cual hace que esas obras rebosen de creatividad y sean únicas.

El capítulo XIV Barro policromado, Izúcar de Matamoros, Puebla es el testimonio de la autora del capítulo Virginia Morgan. Artesana que desde hace décadas trabaja este material. El testimonio de Virginia nos transmite de manera conmovedora el placer de crear bellas obras de arte popular. Para ella el crear es una entrega total, un sentimiento inmenso el de poder ver como algo que ha sido creado hace años sigue siendo bello y reconocido tras el paso del tiempo, un saber que es transmitido a otras y que le permite superarse para poder transmitir esos conocimientos a otros y otras. Un testimonio bello, inquietante y sobre todo ejemplar, pues la enseñanza de la belleza es reflejado en todo momento.

La cuarta parte del libro Entre manos, el arte es iniciada por el capítulo XV El arte popular de las mujeres de Tenango cuya autora es Elena Vázquez y de los Santos. Es el resultado de un proyecto de investigación institucional centrado en la recuperación de la memoria histórica del pueblo. Además, se centra en la búsqueda de los orígenes de los bordados "tenangos". Las mujeres protagonistas de este estudio fueron un grupo de artesanas bordadoras que viven en diferentes comunidades del municipio de Tenango de Doria (Estado de Hidalgo). Los méritos o cuadritos que estas mujeres crean se han ido transformando hoy en día en estampas de la vida de los pueblos que los crean -dibujan y bordan-. Son fragmentos de su vida, su historia y su identidad. Este texto nos va a ir desentrañando como las mujeres de la región se llegan a apropiar de su entorno, de una cosmovisión milenaria de sus culturas y pueblos, de los elementos del propio paisaje y que son plasmados punto por punto en los bordados que elaboran, todo ello con el fin de significar y transmitir la vida de sus comunidades en hilos de colores y trozos de tela. Puros retratos y realidades de sus vidas, identidades, culturas y pueblos.

Mujeres y música popular de bandas. Una perspectiva general es un capítulo "rara avis". Este capítulo XVI cuya autora es Vilka Elisa Castillo Silva viene a analizar un contexto artístico muy poco tratado, por no decir casi ni mencionado, como lo es el del arte popular musical de las bandas de viento $\mathrm{y}$ menos cuando se trata de la incorporación de las mujeres en ellas como artistas. La autora, instrumentalista e investigadora de la música de bandas de viento, las cuales son fundamentales en las agrupaciones musicales de la vida comunitaria en México desde tiempos lejanos, apenas las mujeres han participado o participan de estas agrupaciones musicales. Vilka puntualiza como posibles causas algunos elementos de género como puntos de exclusión de niñas y mujeres en dichas agrupaciones, tales como: le origen militar de la propia agrupación, la necesidad de salir de sus hogares y comunidades para poder profesionalizarse -algo que aún no está muy bien visto en comunidades rurales-, los horarios y 
lugares en que son requeridos los servicios de las bandas -lugares y horarios que son proclives a la violencia machista en un país donde los feminicidios siguen a la orden del día-, entre otras muchas causas que marcan y marcarán la participación de las mujeres en este tipo de agrupaciones "bandas de viento". La autora hace referencia a cómo son las construcciones patriarcales que constituyen y forman este tipo de agrupaciones las que niegan el desarrollo de las mujeres en estos espacios musicales.

El capítulo XVII titulado La estética ritual metafórica del corazonar: memorias infantiles en la puntada cimarrona de mujeres afroecuatorianas. Texto que nos hace viajar hasta Ecuador cuya autora es Marisol Cárdenas Oñate nos remite a lo importante que es reflexionar sobre algunas estéticas que socialmente y desde la formalidad artística son devaluadas, pero que son de una inmensa riqueza creativa y social. En este caso se trata de las muñecas cimarronas, confeccionadas por las mujeres afroecuatorianas quienes además de mostrar su belleza creativa, su imaginario social e identidad, también crean espacios lúdicos para la comunidad, espacios de sanación, de recuerdos y emociones, pues esas esculturas blandas y de trapo, son narraciones autoetnográficas y anecdotarias.

El último capítulo el XVIII La maestra artesana es un texto escrito por Isabel Castillo es otra de los testimonios narrativos de artistas que, en el caso que nos ocupa, narra su larga trayectoria como creadora de objetos de barro policromado.

Todos y cada uno de los textos recogidos en este libro nos muestran las condiciones de desigualdad en la que viven las mujeres en los espacios sociales del arte popular, aun cuando ellas son las creadoras en la mayor parte de las ocasiones. Mostrando cómo el arte popular creado por ellas es un arte que va desde lo social colectivo a lo intimista y cotidiano, pero siempre con una creatividad desbordante y con una visión de colaboración, creación y enseñanza. La desigualdad de la mujer creadora deriva de su propia condición del ser mujer, por ello es por lo que se precisa la visión del género en todos y cada uno de los espacios aquí tratados. Si ya el mundo del arte popular está pauperizado, el mero hecho de ser mujer artista es un tope más al desarrollo y al bienestar de la persona mujer artista.

Es necesario incluir a la mujer en los espacios de la economía del arte popular, en todos y cada uno de sus procesos, no sólo el de creadora anónima. Este libro hace un llamamiento a esa necesidad.

Para finalizar esta reseña quisiera mencionar la riqueza de la diversidad aquí narrada, diversidad de obras, de culturas, de mujeres, de estilos de vida, de creaciones de materiales pero que se juntan en un mismo campo artístico como lo es el arte popular. Es entonces una creatividad diversa que se integra dentro de un imaginario popular femenino igualmente diverso.

Repitiendo y abundando en lo descrito en el inicio, esta es una obra que muestra como es necesaria la mirada y la acción del feminismo dentro del arte popular, así como es necesaria la perspectiva o mirada de género con el fin de erradicar la falta de oportunidades a las creadoras, permitiendo que salgan del anonimato, de la invisibilidad y de la inmanencia que es estar detrás del taller.

Antes de finalizar del todo, no podemos dejar de mencionar la bocanada de aire fresco que es el tener una visión no euro-gringo céntrica -con permiso de Eli Bartra hago uso del término por ella mentado- de las cosas, de la vida, de la creatividad y sobre todo de la importancia del arte popular.

José Manuel Méndez Tapia

Benemérita Universidad Autónoma de Puebla, México muriedades22@gmail.com

Recibida: 25-8-2016 Aceptada:19-9-2016

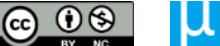

